\title{
STRENGTH TESTING AND ANALYSIS OF FATIGUE CRACK GROWTH IN SELECTED AIRCRAFT MATERIALS
}

\author{
Sylwester Kłysz, Janusz Lisiecki \\ Air Force Institute of Technology, Warsaw, Poland
}

Abstract

The study has been intended to determine the most essential mechanical and fatigue properties as well as impact strength of the 30HGSNA steel, to gain own data on the above-mentioned characteristics of materials to be used further on in numerical analyses of life estimates of aeronautical structural components. The scope of the study comprised the following assignments:

- determination of the most fundamental mechanical properties and impact strength of materials,

- low-cycle fatigue testing and evaluation of the Manson-Coffin curves,

- high-cycle fatigue testing and evaluation of the Wöhler curves,

- investigation into fatigue crack growth rates at constant and variable load-cycle amplitudes (determination of curves da/dN $=f(\Delta K, R)$, coefficients in Paris and NASGRO equations, coefficients in the Wheeler models of delay, the value of $\left.K_{t h}(R)\right)$,

- crack toughness testing under the plane-state-of-strain conditions at room temperature (determination of the $\left.K_{I c}(R)\right)$.

The strength/fatigue testing was carried out in the Laboratory for Materials Strength Testing of the AFIT's Division for Aeronautical Systems Reliability and Safety, the lab being accredited by the Polish Centre for Accreditation (Accreditation Certificate No.: AB 430).

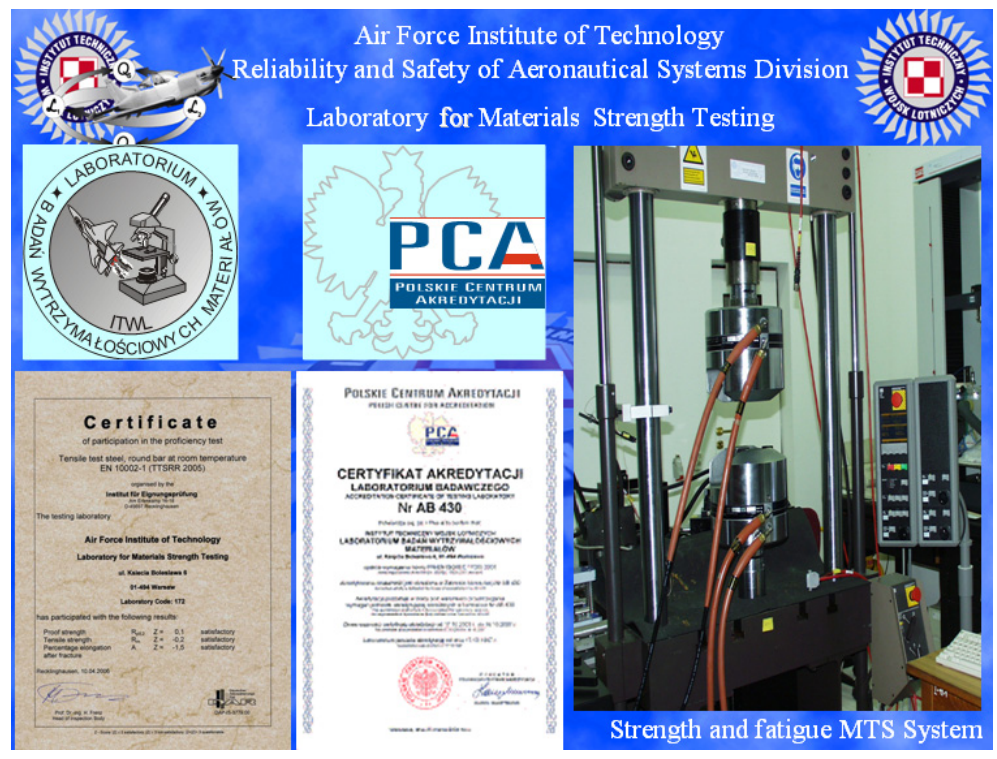

\section{Preparing for the testing work}

The 30HGSNA is a constructional alloy steel intended for the manufacturing of structural components exposed to exceptionally high loads. The steel purchased was in the form of a bar of the diameter $\varnothing=60 \mathrm{~mm}$. Table 1 shows properties of the material of the bar manufactured at the Batory Steelworks according to the Engineering Acceptance Report No. 212/P/89, and specifications for the steel following the Polish Standard PN-72/H-84035. 
Tab. 1. Properties of the material of the bar according to the Engineering Acceptance Report, and specifications following the Polish Standard PN-72/H-84035

\begin{tabular}{|c|c|c|c|c|c|c|c|}
\hline \multicolumn{8}{|c|}{ Chemical composition [\%] } \\
\hline & $\mathrm{C}$ & $\mathrm{Mn}$ & $\mathrm{Si}$ & $\mathrm{P}_{\max }$ & & $\mathrm{Cr}$ & $\mathrm{Ni}$ \\
\hline & $0.28 \div 0.30$ & 1.16 & 1.08 & 0.024 & & 0.93 & 1.58 \\
\hline PN-72/H-84035 & $0.27 \div 0.34$ & $1.00 \div 1.30$ & $0.90 \div 1.20$ & 0.030 & & $0.90 \div 1.20$ & $1.40 \div 1.80$ \\
\hline \multicolumn{8}{|c|}{$\begin{array}{l}\text { Mechanical properties } \\
\text { : quench hardening } 900^{0} \mathrm{C} 20^{\prime} \text { oil, tempering } 250^{\circ} \mathrm{C} 3 \mathrm{~h} \text { air) }\end{array}$} \\
\hline & $\begin{array}{c}R_{m} \\
{[\mathrm{MPa}]}\end{array}$ & $\begin{array}{c}R_{e} \\
{[\mathrm{MPa}]}\end{array}$ & $\begin{array}{c}A \\
{[\%]}\end{array}$ & & & $\begin{array}{l}K C U 2 \\
{\left[\mathrm{~J} / \mathrm{cm}^{2}\right]}\end{array}$ & $H B$ \\
\hline & $1725 \div 1775$ & $1505 \div 153$ & $13 \div 14$ & & & $90 \div 95$ & 2.8 \\
\hline $\mathrm{PN}-72 / \mathrm{H}-84035$ & $\min .1620$ & $\min .137$ & $\min .9$ & $\mathrm{mi}$ & & $\min .60$ & - \\
\hline
\end{tabular}

The following specimens were prepared for the tests:

- cylindrical ones for strength and static tensile testing,

- sand-clock ones for low-cycle fatigue (LCF) testing,

- cylindrical ones for high-cycle fatigue (HCF) testing,

- round compact tension (RCT) ones for testing both fatigue-crack propagation rate and crack toughness.

Shapes and dimensions of the specimens have been shown in Figs $1 \div 4$.

The quench hardening was carried out in oil, starting from $900^{\circ} \mathrm{C}$; the tempering was carried out at temperature ranging from 240 to $250^{\circ} \mathrm{C}$ for three hours. After that, the specimens were cooled in steady air. What followed the thermal treatment was grinding of the specimens.

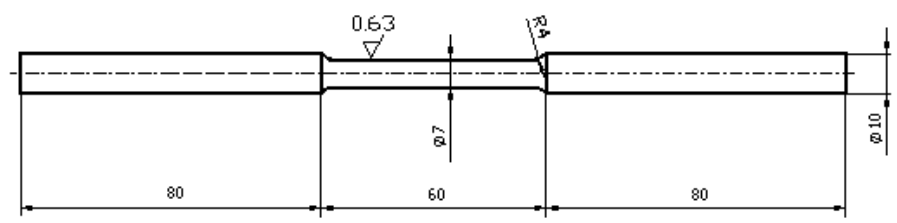

Fig. 1. Shape and dimensions of an exemplary specimen for strength testing

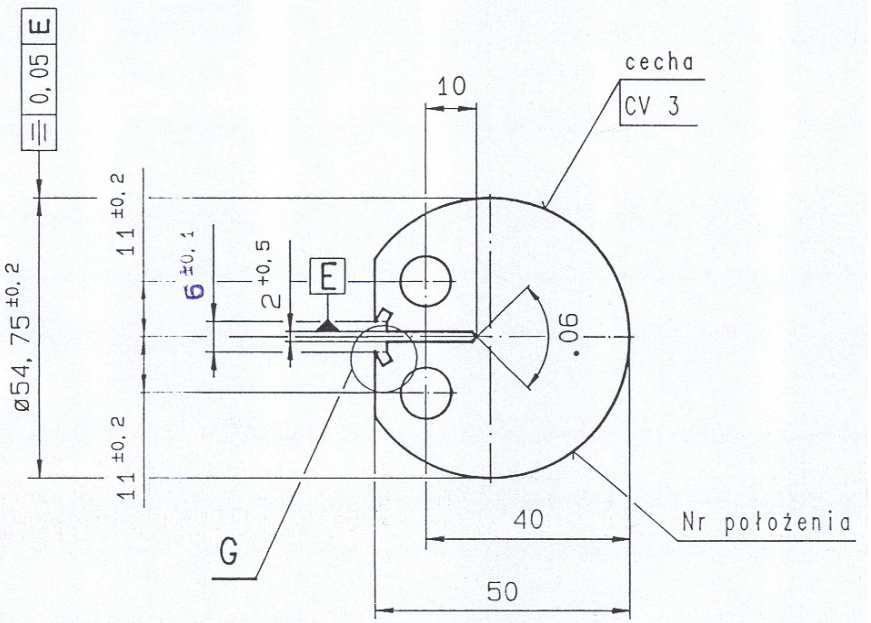

Fig. 2. Shapes and dimensions of specimens to examine fatigue-crack propagation rates and crack toughness 


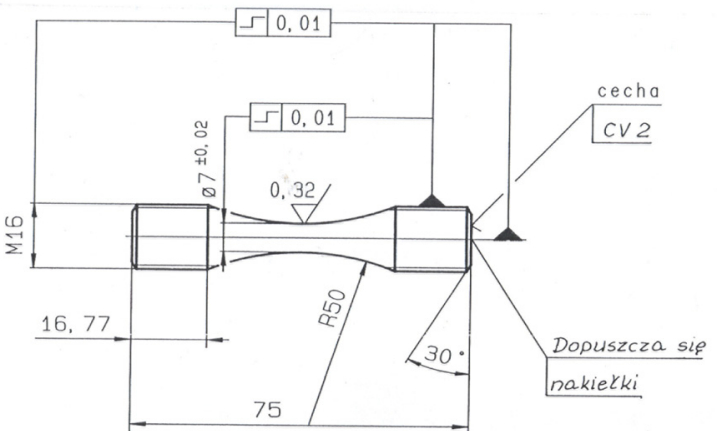

Fig. 3. Shapes and dimensions of specimens for low-cycle fatigue (LCF) testing

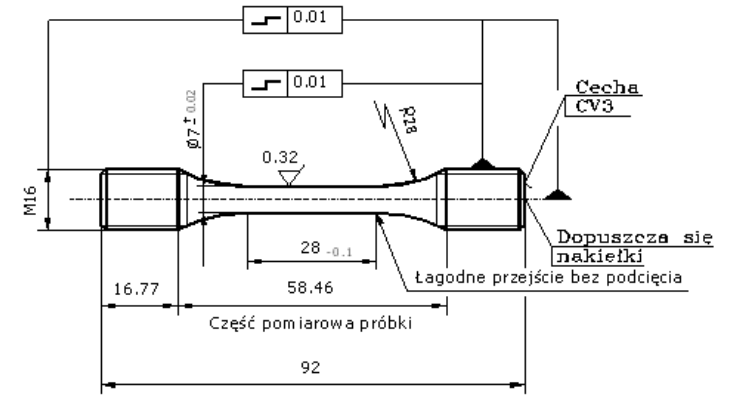

Fig. 4. Shapes and dimensions of specimens for high-cycle fatigue (HCF) testing

Findings on mechanical properties of the 30HGSNA steel

\begin{tabular}{|c|c|c|c|c|c|c|c|c|c|c|}
\hline $\begin{array}{c}\mathrm{Nr} \\
\text { próbki }\end{array}$ & $d_{0}$ & $L_{0}$ & $R_{0,05}$ & $R_{0,2}$ & $R_{m}$ & $R_{m r z}$ & $A$ & $n$ & $K$ & $E$ \\
\hline $2 / 05 / 1$ & 6.95 & 50 & 420 & 450 & 795 & 910 & - & 0.190 & 1374 & 200600 \\
\hline $2 / 05 / 2$ & 6.78 & 50 & 1160 & 1340 & 1655 & 1695 & - & 0.110 & 2700 & 202300 \\
\hline $2 / 05 / 3$ & 6.85 & 50 & 1145 & 1325 & 1655 & 1700 & - & 0.110 & 2658 & 201100 \\
\hline $2 / 05 / 4$ & 6.83 & 50 & 1150 & 1315 & 1640 & 1685 & - & 0.105 & 2544 & 194000 \\
\hline $2 / 05 / 5$ & 6.80 & 50 & 1150 & 1320 & 1640 & 1685 & - & 0.105 & 2554 & 200200 \\
\hline $2 / 05 / 36$ & 7.92 & 30 & 1200 & 1360 & 1670 & 1730 & $13.7^{*}$ & 0.100 & 2552 & 197300 \\
\hline $2 / 05 / 61$ & 4.95 & 25 & 1230 & 1380 & 1700 & 1755 & 11.1 & 0.090 & 2467 & 199700 \\
\hline $2 / 05 / 62$ & 4.96 & 25 & 1230 & 1390 & 1700 & 1750 & - & 0.090 & 2475 & 197500 \\
\hline $2 / 05 / 63$ & 4.99 & 25 & 1240 & 1400 & 1715 & 1765 & 11.2 & 0.090 & 2484 & 198800 \\
\hline $2 / 05 / 64$ & 4.99 & 25 & 1175 & 1365 & 1715 & 1800 & 13.0 & 0.100 & 2508 & 198700 \\
\hline $2 / 05 / 132$ & 7.87 & 30 & 1175 & 1345 & 1670 & 1705 & - & 0.100 & 2483 & 206800 \\
\hline $2 / 05 / 133$ & 5.96 & 50 & 1235 & 1415 & 1750 & 1805 & $7.6^{* *}$ & 0.105 & 2694 & 201600 \\
\hline $2 / 05 / 134$ & 5.98 & 50 & 1280 & 1430 & 1735 & 1785 & $7.5^{* *}$ & 0.090 & 2497 & 198900 \\
\hline $2 / 05 / 135$ & 5.99 & 50 & 1290 & 1425 & 1730 & 1785 & $7.6^{* *}$ & 0.085 & 2500 & 195500 \\
\hline $2 / 05 / 136$ & 5.98 & 50 & 1330 & 1450 & 1720 & 1760 & $7.4^{* *}$ & 0.080 & 2441 & 197300 \\
\hline $2 / 05 / 137$ & 6.93 & 50 & 1220 & 1395 & 1730 & 1800 & $9.5^{* *}$ & 0.100 & 2638 & 201800 \\
\hline $2 / 05 / 138$ & 6.79 & 50 & 1225 & 1400 & 1735 & 1800 & $9.0^{* *}$ & 0.090 & 2526 & 194500 \\
\hline $2 / 05 / 139$ & 6.90 & 50 & 1235 & 1405 & 1730 & 1800 & $7.0^{* *}$ & 0.095 & 2521 & 197700 \\
\hline $2 / 05 / 140$ & 5.76 & 50 & 1240 & 1400 & 1725 & 1780 & $8.1^{* *}$ & 0.105 & 2690 & 207300 \\
\hline $2 / 05 / 141$ & 6.03 & 50 & 1225 & 1400 & 1720 & 1770 & $7.6^{* *}$ & 0.100 & 2630 & 198000 \\
\hline $2 / 05 / 142$ & 5.84 & 50 & 1250 & 1410 & 1715 & 1770 & $7.7^{* *}$ & 0.090 & 2511 & 203200 \\
\hline
\end{tabular}


On the grounds of the conducted testing work it has been found that the mechanical properties of the 30HGSNA steel are as follows:

- offset yield strength

$$
\begin{gathered}
R_{0,05}=1220 \mathrm{MPa} \pm 1.82 \% \\
R_{0,2}=1385 \mathrm{MPa} \pm 1.24 \% \\
R_{m}=1700 \mathrm{MPa} \pm 0.90 \% \\
A=12.2 \% \pm 10.64 \% \\
E=199600 \mathrm{MPa} \pm 0.80 \% \\
R_{m, r z}=1755 \mathrm{MPa} \pm 0.34 \% \\
n=0.100 \pm 3.60 \% \\
K=2554 \mathrm{MPa} \pm 1.46 \%
\end{gathered}
$$$$
\text { - offset yield strength }
$$$$
\text { - percentage elongation }
$$$$
\text { - Young's modulus }
$$$$
\text { - true tensile strength }
$$

All the values found are average values calculated with the expanded uncertainty of the average at the level of confidence $95 \%$.

Results of strength tests carried out at AFIT have been verified under the Excellence Testing Project, with approximately 100 laboratories from all over Europe participating. The belowpresented figures show the position of test results gained at AFIT against those obtained by other laboratories - AFIT has been encoded as Laboratory No.172.

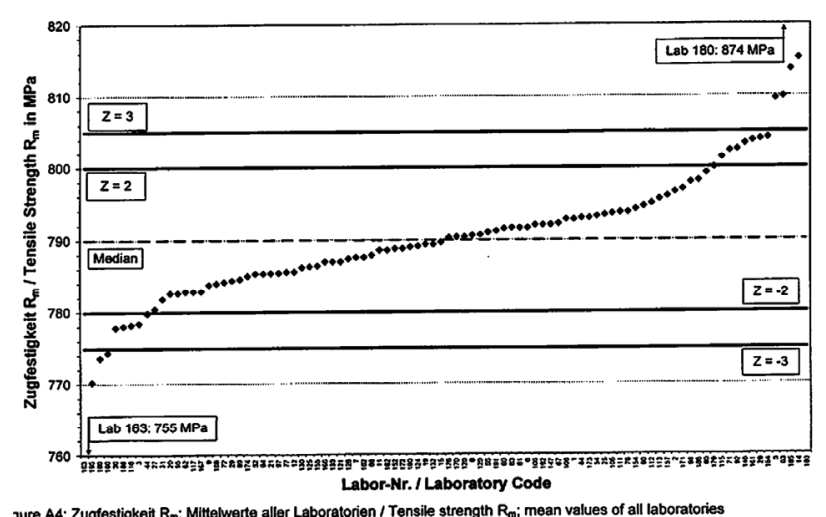

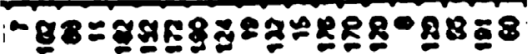
abor-Nr. I Laboratory

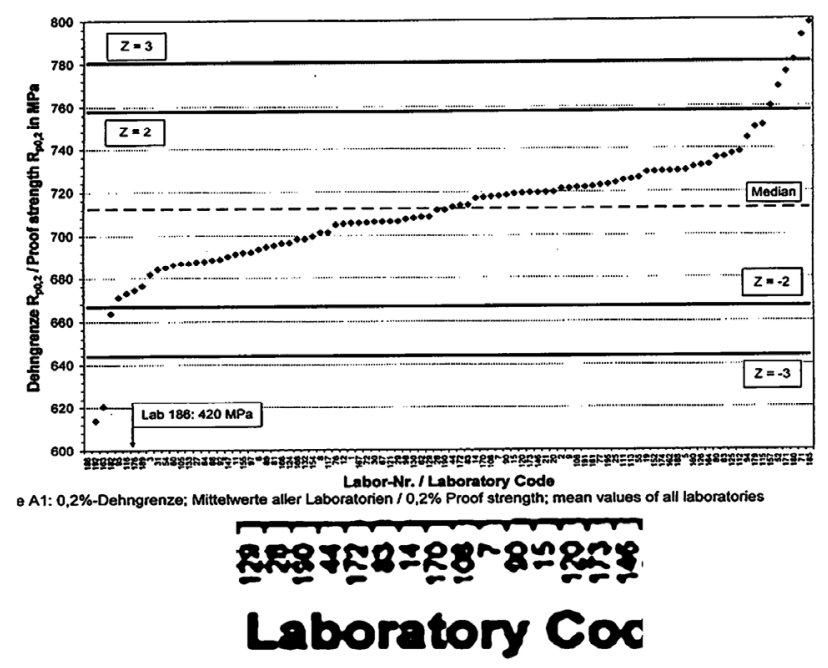

\section{Proficiency Test \\ Tensile Test Steel}

Round bar at room temperature

(TTSRR 2005)

Final Report

April, $7^{\text {th }} 2006$

Institut fưr Eignungsprưưun Am Errenkamp 16-18, D-45657 Recklinghausen

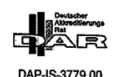

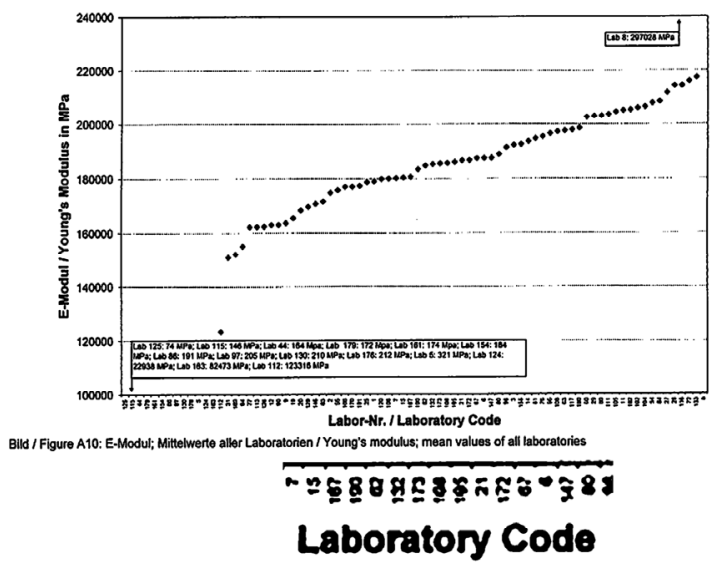

Fig.5. The Excellence Testing results. 


\section{Results of low-cycle fatigue tests}

Tests that consist in the evaluation of fatigue life $\left(2 N_{f}\right)$ against deformation range $(\Delta \varepsilon)$ have allowed of the determination of the curve $\Delta \varepsilon-2 N_{f}$ (Fig.6) using the Manson-Coffin equation of the following form:

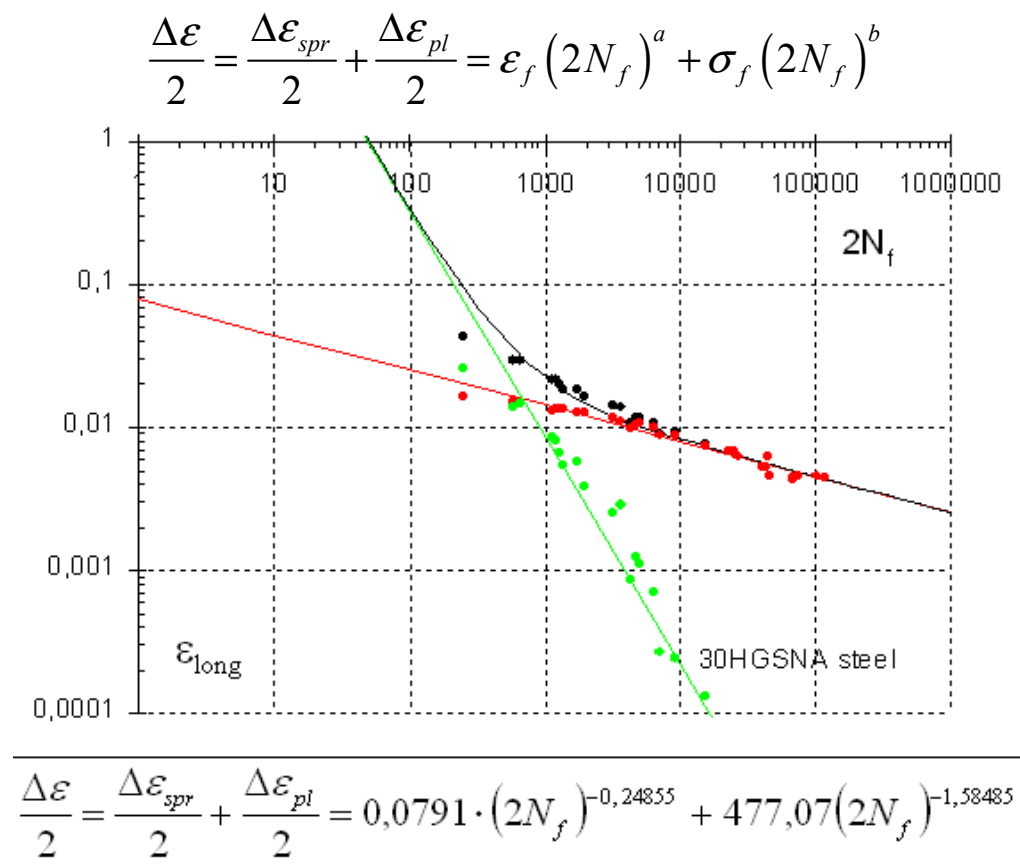

Fig. 6. Low-cycle fatigue results

\section{Results of high-cycle fatigue tests}

Tests that consist in the evaluation of fatigue life $\left(2 N_{f}\right)$ against the stress amplitude $\left(\sigma_{\alpha}\right)$ have allowed of the determination of the curve $\sigma_{\alpha} 2 N_{f}$ (Fig.7) using the Morrow equation of the following form:

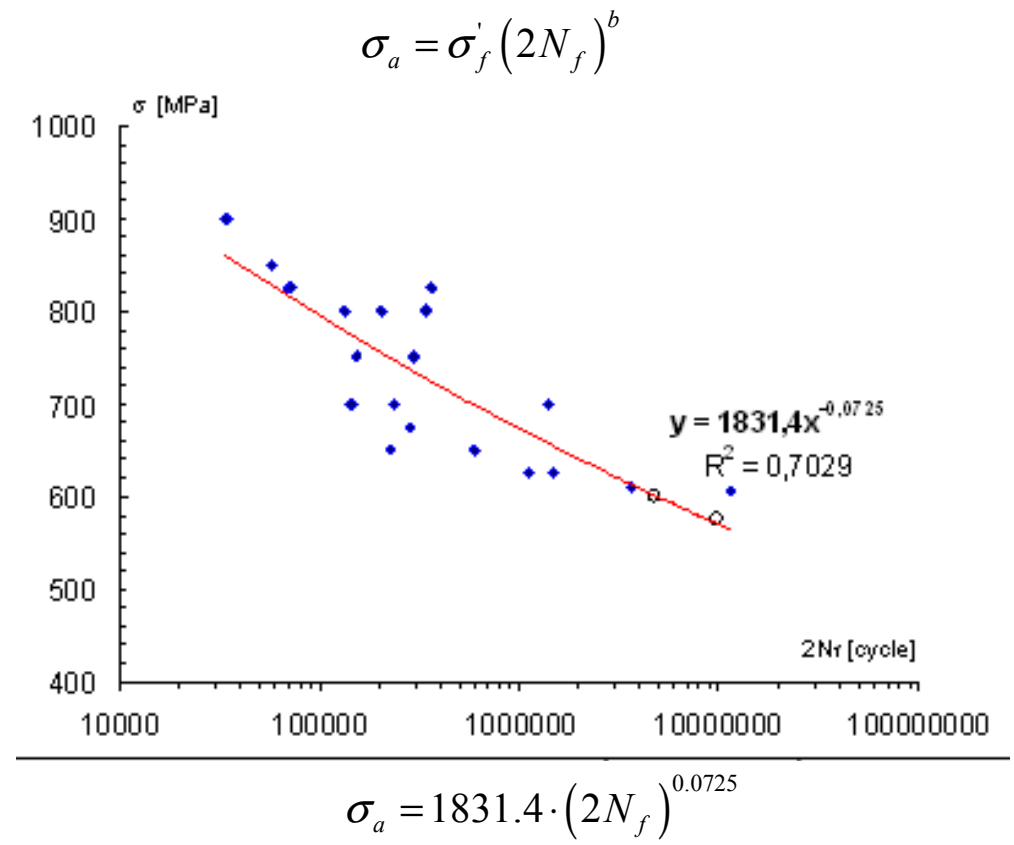

Fig. 7. High-cycle fatigue results 


\section{Results of constant-load-amplitude fatigue crack growth rate (FCGR) testing}

Precracks of length up to $a=12.5 \mathrm{~mm}$ were produced in the specimens at $K_{\text {konc }}=30 \mathrm{MPa} \sqrt{\mathrm{m}}$. Determined were coefficients in the Paris and NASGRO equations that describe the propagation curves. The Paris equation has the following form: $\frac{d a}{d N}=C(\Delta K)^{m}$

Coefficients included therein allow of describing propagation curves for different stress intensity factor ranges $\Delta K$ (threshold, steady, critical ones) for individual specimens are presented in Table 4.

\section{Table 4. Results of computations of Paris equation coefficients for respective specimens}

\begin{tabular}{|c|c|c|c|c|c|c|}
\hline \multirow{2}{*}{ Specimen } & \multirow{2}{*}{$\boldsymbol{R}$} & \multirow{2}{*}{$m$} & \multirow{2}{*}{$C$} & \multirow{2}{*}{ Correlation coefficient } & \multicolumn{2}{|c|}{ Regression range } \\
\hline & & & & & $d a / d N_{\min }$ & $d a / d N_{\max }$ \\
\hline $2-05-71$ & 0.10 & 2.856 & $1.8395 \mathrm{E}-08$ & 0.9679 & $1.00 \mathrm{E}-05$ & $1.00 \mathrm{E}-04$ \\
\hline $2-05-71$ & 0.10 & 2.814 & $1.8719 \mathrm{E}-08$ & 0.9948 & $6.00 \mathrm{E}-04$ & $1.00 \mathrm{E}-05$ \\
\hline $2-05-66$ & 0.05 & 2.750 & $2.1755 \mathrm{E}-08$ & 0.9969 & $1.00 \mathrm{E}-06$ & $3.00 \mathrm{E}-04$ \\
\hline $2-05-66$ & 0.05 & 2.803 & $1.7778 \mathrm{E}-08$ & 0.9664 & $2.00 \mathrm{E}-06$ & $5.00 \mathrm{E}-04$ \\
\hline $2-05-65$ & 0.05 & 2.661 & $2.8916 \mathrm{E}-08$ & 0.9936 & $2.40 \mathrm{E}-06$ & $5.20 \mathrm{E}-04$ \\
\hline $2-05-124$ & 0.10 & 2.816 & $1.9258 \mathrm{E}-08$ & 0.9927 & $7.00 \mathrm{E}-06$ & $2.00 \mathrm{E}-04$ \\
\hline $2-05-119$ & 0.10 & 3.015 & $9.3170 \mathrm{E}-09$ & 0.9963 & $2.00 \mathrm{E}-06$ & $3.50 \mathrm{E}-04$ \\
\hline $2-05-77$ & 0.10 & 2.804 & $1.9788 \mathrm{E}-08$ & 0.9871 & $1.50 \mathrm{E}-05$ & $1.00 \mathrm{E}-03$ \\
\hline $2-05-119$ & 0.10 & 2.921 & $1.1330 \mathrm{E}-08$ & 0.9969 & $2.00 \mathrm{E}-05$ & $7.00 \mathrm{E}-04$ \\
\hline $2-05-120$ & 0.09 & 3.321 & $2.4786 \mathrm{E}-09$ & 0.9970 & $1.00 \mathrm{E}-06$ & $1.10 \mathrm{E}-04$ \\
\hline $2-05-76$ & 0.10 & 3.019 & $8.5387 \mathrm{E}-09$ & 0.9905 & $5.00 \mathrm{E}-06$ & $3.00 \mathrm{E}-04$ \\
\hline $2-05-124$ & 0.10 & 2.741 & $2.1695 \mathrm{E}-08$ & 0.9901 & $7.00 \mathrm{E}-05$ & $1.00 \mathrm{E}-03$ \\
\hline $2-05-77$ & 0.10 & 8.048 & $4.7262 \mathrm{E}-17$ & 0.9359 & $7.00 \mathrm{E}-04$ & $2.30 \mathrm{E}-02$ \\
\hline $2-05-119$ & 0.10 & 8.490 & $9.4914 \mathrm{E}-18$ & 0.9037 & $7.00 \mathrm{E}-04$ & $1.00 \mathrm{E}-02$ \\
\hline $2-05-77$ & 0.10 & 9.371 & $2.5037 \mathrm{E}-19$ & 0.9522 & $1.00 \mathrm{E}-03$ & $2.30 \mathrm{E}-02$ \\
\hline $2-05-124$ & 0.10 & 7.113 & $9.4344 \mathrm{E}-16$ & 0.9565 & $1.00 \mathrm{E}-03$ & $4.00 \mathrm{E}-02$ \\
\hline $2-05-76$ & 0.10 & 9.212 & $3.3835 \mathrm{E}-19$ & 0.8817 & $1.00 \mathrm{E}-03$ & $1.00 \mathrm{E}-02$ \\
\hline $2-05-119$ & 0.50 & 2.771 & $2.7158 \mathrm{E}-08$ & 0.9891 & $1.00 \mathrm{E}-06$ & $7.00 \mathrm{E}-05$ \\
\hline $2-05-72$ & 0.50 & 2.915 & $2.2405 \mathrm{E}-08$ & 0.9788 & $4.30 \mathrm{E}-06$ & $1.00 \mathrm{E}-04$ \\
\hline $2-05-73$ & 0.50 & 2.659 & $3.8849 \mathrm{E}-08$ & 0.9777 & $1.00 \mathrm{E}-06$ & $3.00 \mathrm{E}-05$ \\
\hline $2-05-120$ & 0.50 & 3.346 & $4.2326 \mathrm{E}-09$ & 0.9912 & $1.00 \mathrm{E}-06$ & $6.00 \mathrm{E}-05$ \\
\hline $2-05-124$ & 0.50 & 2.828 & $2.4071 \mathrm{E}-08$ & 0.9912 & $2.60 \mathrm{E}-06$ & $1.00 \mathrm{E}-04$ \\
\hline $2-05-73$ & 0.50 & 3.185 & $1.0225 \mathrm{E}-08$ & 0.9936 & $1.00 \mathrm{E}-05$ & $3.00 \mathrm{E}-04$ \\
\hline $2-05-84$ & 0.50 & 3.517 & $4.0724 \mathrm{E}-09$ & 0.9556 & $5.00 \mathrm{E}-04$ & $1.00 \mathrm{E}-02$ \\
\hline $2-05-72$ & 0.50 & 3.040 & $1.5690 \mathrm{E}-08$ & 0.9918 & $4.00 \mathrm{E}-04$ & $4.00 \mathrm{E}-03$ \\
\hline $2-05-84$ & 0.50 & 9.128 & $3.1555 \mathrm{E}-17$ & 0.4794 & $5.00 \mathrm{E}-04$ & $1.00 \mathrm{E}-02$ \\
\hline $2-05-72$ & 0.50 & 8.397 & $4.0201 \mathrm{E}-16$ & 0.7342 & $4.30 \mathrm{E}-06$ & $4.00 \mathrm{E}-04$ \\
\hline $2-05-74$ & 0.80 & 3.215 & $2.1108 \mathrm{E}-08$ & 0.9380 & $1.00 \mathrm{E}-06$ & $1.00 \mathrm{E}-05$ \\
\hline $2-05-74$ & 0.80 & 2.848 & $3.6587 \mathrm{E}-08$ & 0.9563 & $1.20 \mathrm{E}-06$ & $1.50 \mathrm{E}-05$ \\
\hline $2-05-120$ & 0.80 & 3.995 & $2.1848 \mathrm{E}-09$ & 0.9237 & $1.60 \mathrm{E}-06$ & $8.00 \mathrm{E}-05$ \\
\hline $2-05-67$ & 0.80 & 2.910 & $3.2668 \mathrm{E}-08$ & 0.9456 & $2.40 \mathrm{E}-06$ & $4.00 \mathrm{E}-05$ \\
\hline $2-05-78$ & 0.80 & 3.310 & $1.5736 \mathrm{E}-08$ & 0.9406 & $3.60 \mathrm{E}-06$ & $1.00 \mathrm{E}-04$ \\
\hline 2-05-79 & 0.80 & 4.165 & $2.3139 \mathrm{E}-09$ & 0.9341 & $3.80 \mathrm{E}-06$ & $1.00 \mathrm{E}-04$ \\
\hline $2-05-124$ & 0.80 & 3.017 & $2.5941 \mathrm{E}-08$ & 0.9151 & $9.00 \mathrm{E}-06$ & $4.60 \mathrm{E}-05$ \\
\hline $2-05-67$ & 0.80 & 11.886 & $1.2537 \mathrm{E}-17$ & 0.8216 & $4.00 \mathrm{E}-05$ & $7.00 \mathrm{E}-03$ \\
\hline $2-05-78$ & 0.80 & 9.644 & $5.0882 \mathrm{E}-15$ & 0.6991 & $5.25 \mathrm{E}-05$ & $4.00 \mathrm{E}-03$ \\
\hline $2-05-78$ & 0.80 & 8.333 & $1.7890 \mathrm{E}-13$ & 0.4519 & $1.00 \mathrm{E}-04$ & $4.00 \mathrm{E}-03$ \\
\hline $2-05-79$ & 0.80 & 10.984 & $1.9669 \mathrm{E}-16$ & 0.6991 & $1.00 \mathrm{E}-04$ & $4.20 \mathrm{E}-03$ \\
\hline $2-05-79$ & 0.80 & 9.587 & $6.8176 \mathrm{E}-15$ & 0.7344 & $5.25 \mathrm{E}-05$ & $4.20 \mathrm{E}-03$ \\
\hline
\end{tabular}


Since the Paris equation takes no account of the dependence of crack propagation curves on the stress ratio $R$, a relationship between values of coefficients $C$ and $m$ for particular curves was found, i.e. for test results gained at $R=0.1 ; 0.5$; and 0.8 - see Fig. 8 .

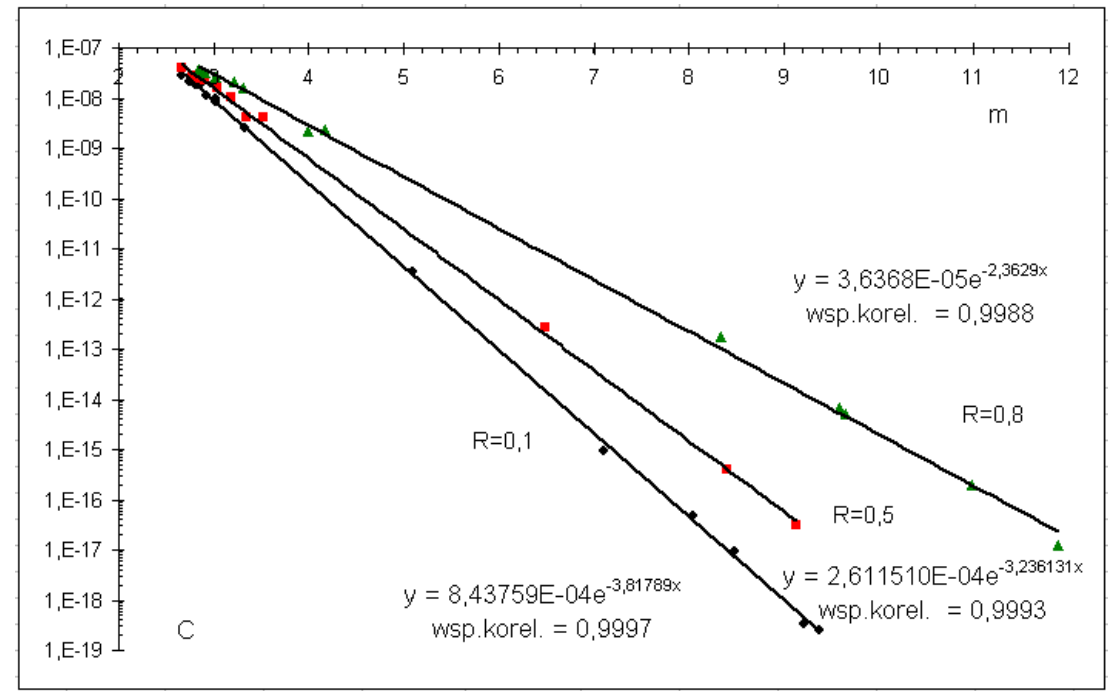

Fig. 8. Relationship between values of coefficients $C$ and $m$ for particular curves ( $i . e$. for test results gained at $R=0.1 ; 0.5$; and 0.8 )

The relationships between the $C$ and $m$ coefficients and $R$ (for tests conducted at different stress ratios $R$ ) in the semi-log coordinate system are linear and described with equations of the following type:

$$
C=a_{1, R} e^{a_{2, R} m}
$$

where coefficients $a_{1, R}$ and $a_{2, R}$ take values as shown in Fig. 8.

In specific cases the Paris equation takes the following forms:

- $\quad$ for $R=0.1$

$$
\frac{d a}{d N}=\left(8.438 \cdot 10^{-4}\right) e^{(-3.818) m}(\Delta K)^{m}
$$

- $\quad$ for $R=0.5$

$$
\frac{d a}{d N}=\left(2.612 \cdot 10^{-4}\right) e^{(-3.236) m}(\Delta K)^{m}
$$

- $\quad$ for $R=0.8$

$$
\frac{d a}{d N}=\left(3.637 \cdot 10^{-5}\right) e^{(-2.363) m}(\Delta K)^{m}
$$

Since there are linear relationship between both the coefficients, i.e. $a_{1, R}$ and $a_{2, R}$, and the stress ratio $R$, a generalized form of the Paris equation for a given material can be written down:

$$
\frac{d a}{d N}=\left(9.26 \cdot 10^{-4}-1.17 \cdot 10^{-3} R\right) e^{(-4.093+2.045 R) m}(\Delta K)^{m}
$$

It means that if some pre-set value of the $m$ coefficient in the Paris equation is taken from some specific range of $\Delta K$, the value of the $C$ coefficient can be calculated from the above written equation - within the range of the stress ratio $R$ changing from 0.1 to 0.8 . 


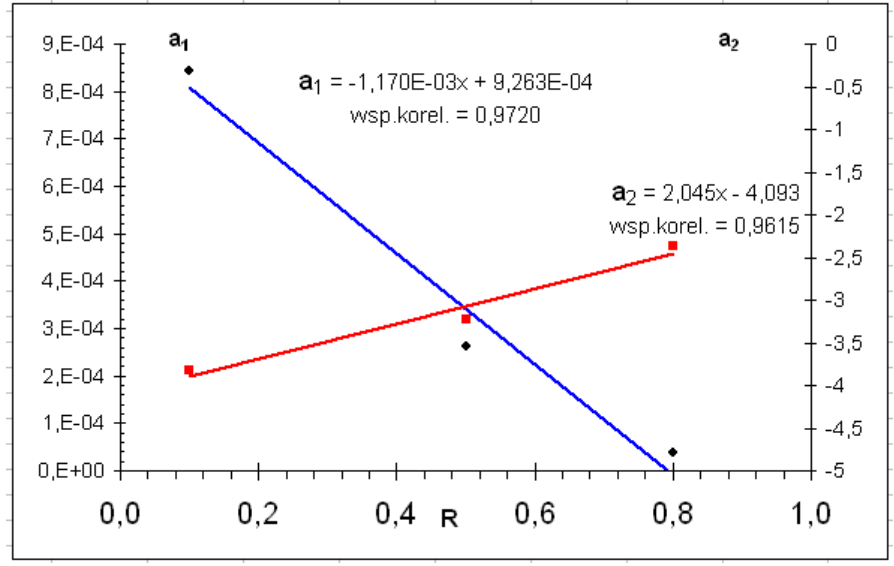

Fig. 9. How values of $a_{1, R}$ and $a_{2, R}$ coefficients depend on stress ratio $R$

The NASGRO equation (by Forman \& Newman from NASA, de Koning from NLR, and Henriksen from ESA) takes the following form:

$$
\frac{d a}{d N}=C\left[\left(\frac{1-f}{1-R}\right) \Delta K\right]^{n} \frac{\left(1-\frac{\Delta K_{t h}}{\Delta K}\right)^{\prime}}{\left(1-\frac{K_{\max }}{K_{c r i t}}\right)^{q}}
$$

where:

$$
\begin{aligned}
f=\frac{K_{o p}}{K_{\max }}=\left\{\begin{array}{lc}
\max \left(R, A_{0}+A_{1} R+A_{2} R^{2}+A_{3} R^{3}\right) & R \geq 0 \\
A_{0}+A_{1} R & -2 \leq R<0 \\
A_{0}-2 A_{1} & R<-2
\end{array}\right. \\
A_{0}=\left(0.825-0.34 \alpha+0.05 \alpha^{2}\right)\left[\cos \left(\frac{\pi}{2} S_{\max } / \sigma_{0}\right)\right]^{1 / \alpha} \\
A_{1}=(0.415-0.071 \alpha) S_{\text {max }} / \sigma_{0} \\
A_{2}=1-A_{0}-A_{1}-A_{3} \\
A_{3}=2 A_{0}+A_{1}-1
\end{aligned}
$$

and

$$
\Delta K_{t h}=\Delta K_{0}\left(\frac{a}{a+a_{0}}\right)^{1 / 2} /\left(\frac{1-f}{\left(1-A_{0}\right)(1-R)}\right)^{\left(1+C_{t h} R\right)}
$$

$a$ - initial crack length,

$a_{o} \quad$ - detectable crack length $(0.0015$ " or $0.0000381 \mathrm{~m})$,

$\alpha$ - stress-state-dependent constraint factor,

$S_{\max } / \sigma_{o}$ - the maximum-applied-load-to-yield-stress ratio,

$C_{t h}$ - slope of the propagation curve within threshold range,

$K_{I c}$ - crack toughness (mode I),

$\Delta K_{o}$ - threshold stress intensity factor for $R=0\left(\Delta K_{t h}\right.$ for $\left.R=0\right)$,

$t \quad$ - thickness of the specimen,

$t_{o} \quad$ - reference thickness of the specimen for the plane state of strain

$A_{k}, B_{k}$ - matching parameters, 
with the plane-state-of-strain condition satisfied:

$$
t_{0}=2.5\left(K_{x} / \sigma_{y s}\right)^{2}
$$

and with the asymptotic convergence of $K_{c r i t}$ and $K_{I c}$, if the specimen thickness exceeds the $t_{0}$ :

$$
K_{c r i t} / K_{I c}=1+B_{k} e^{-\left(A_{k} t /\right)^{2}}
$$

Coefficients in the NASGRO equation, which describe the plotted propagation curves, have the following values:

\begin{tabular}{|c|c|c|c|c|c|c|c|c|c|}
\hline $\boldsymbol{K}_{\text {crit }}$ & $\boldsymbol{\alpha}$ & $\boldsymbol{S}_{\max } / \boldsymbol{\sigma}_{\boldsymbol{o}}$ & $\boldsymbol{\Delta K}_{\boldsymbol{o}}$ & $\boldsymbol{a}$ & $\boldsymbol{C}_{\boldsymbol{t h}}$ & $\boldsymbol{C}$ & $\boldsymbol{n}$ & $\boldsymbol{p}$ & $\boldsymbol{q}$ \\
\hline 79 & 2.5 & 0.3 & 4.4 & 0.0125 & 0.2 & $4.9 \mathrm{E}-11$ & 2.54 & 0.25 & 1 \\
\hline
\end{tabular}

Fig. 10. shows degrees of matching these propagation curves to experimental data.

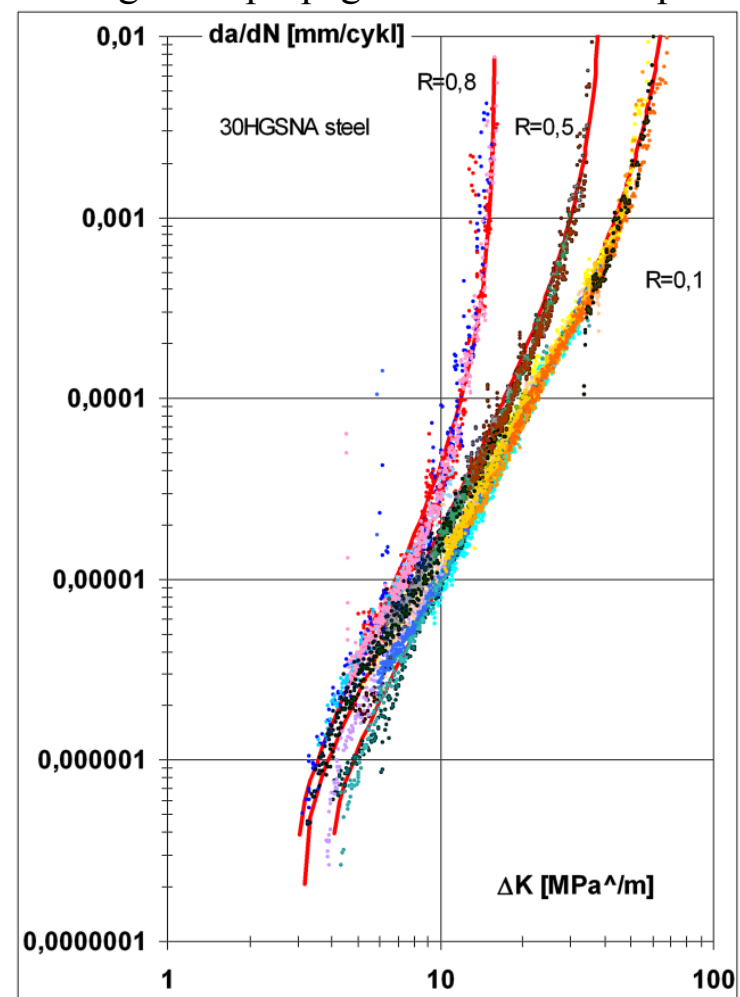

Fig. 10. Fatigue crack growth rates as plotted for different stress ratios $R=0.1 ; 0.5 ; 0.8$

\section{Results of testing crack resistance under plane-state-of-strain conditions}

Test samples to examine the material's crack resistance were cut in the direction transverse to the bar axis (Fig.11). The testing of crack resistance under plane-state-of-strain conditions were carried out using the testing machine MTS 810.23. Round compact tension (RCT) specimens of $W=40 \mathrm{~mm}$ and $B=7 \mathrm{~mm}$ were subjected to tests. Precracks of lengths up to $a=20 \mathrm{~mm}$ were produced in the specimens at $K_{\text {końc }}=30 \mathrm{MPa} \sqrt{\mathrm{m}}$. 


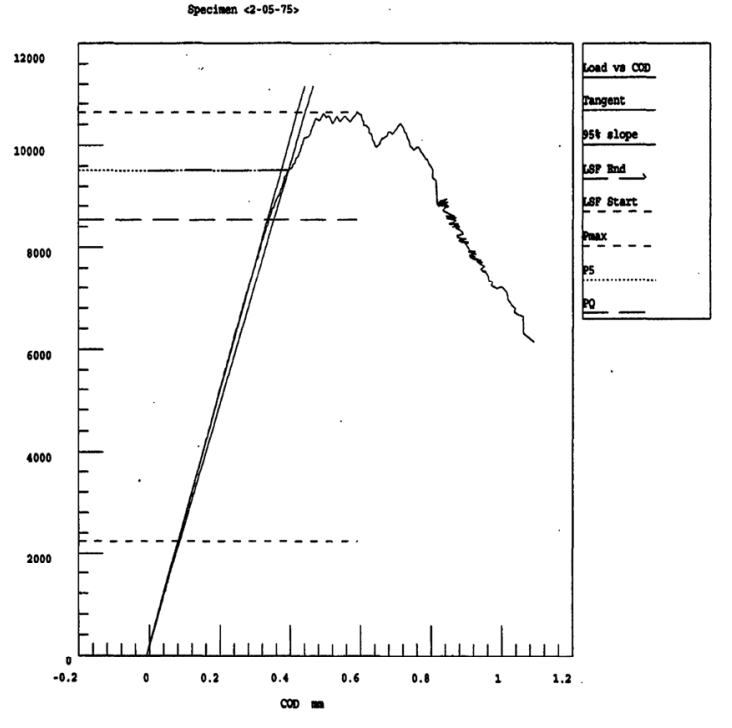

Fig. 11. An exemplary curve resulting from testing the crack resistance under plane-state-of-strain conditions
P5 - 9516.15 $x$

$\max =10631 x$
PQ - $9526.15 \mathrm{k}$

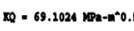

The average found from test results is $69.8 \mathrm{MPa} \sqrt{\mathrm{m}}$. Uncertainty of the average is $\mathrm{U}= \pm 4.36 \%$ at the level of confidence $95 \%$ and coverage factor $k_{p}=2.87$.

The test results satisfy all the criteria provided in the ASTM E 399 standard.

\section{CONCLUSIONS}

1. Values of the yield strength and crack resistance gained from the tests on cylindrical specimens made of the 30HGSNA steel satisfy requirements of the PN-72/H-84035 standard and exceed the required ones by approximately $1.5 \%$ and $5 \%$, respectively. The Young's modulus found for this steel is $E=199300 \mathrm{MPa}$.

2. The low-cycle fatigue (LCF) tests carried out using sand-clock specimens made of the 30HGSNA steel, $7 \mathrm{~mm}$ in diameter, with the PN-84/H-04334 and ASTM E-606 standards followed, allow of the determination of the Manson-Coffin curve for this steel, which takes the following form:

$$
\frac{\Delta \varepsilon}{2}=\frac{\Delta \varepsilon_{s p r}}{2}+\frac{\Delta \varepsilon_{p l}}{2}=0.0791 \cdot\left(2 N_{f}\right)^{-0.24855}+477.07\left(2 N_{f}\right)^{-1.58485}
$$

Because of the sizes of pre-set (in the tests) ranges of strain $\Delta \varepsilon$, and experimentally gained strength of specimens $2 N_{f}$, the above-mentioned relationship can be applied for the number of cycles $N_{f}$ ranging from $3 \cdot 10^{2}$ up to $10^{6}$.

For strength below the number of cycles $3 \cdot 10^{2}$, values of the $\sigma_{f}$ and $b$ coefficients will change considerably. Evaluation thereof requires additional testing work at very large plastic ranges.

3. The crack resistance of the $30 \mathrm{HGSNA}$ steel $K_{l c}$ is $69.8 \mathrm{MPa} \sqrt{\mathrm{m}}$.

\section{REFERENCES}

1. American Society fot Testing and Materials. (2004). Standard Practice for Strain-Controlled Testing. E 606. West Conshonocken, PA: ASTM International. (DOI 10.1520/E0606-04E01)

2. PN-ISO (1996) Metals - Sheets and Tapes - Determination of Tensile Strain-Hardening Exponent. 10275. Polish Committee for Standardization, Warsaw, Poland. 